\title{
Pattern of Vaginal Discharge and Associated Demographic Characteristics among Female Patients Seen at a Gynaecology Clinic in Northern Nigeria
}

\author{
Mohammed-Durosinlorun Amina1 ${ }^{*}$, Muhammad-Idris Zainab ${ }^{2}$, Abubakar Amina1, \\ Ojabo Augustine ${ }^{3}$, Adesiyun Adebiyi ${ }^{4}$ \\ ${ }^{1}$ Department of Obstetrics and Gynaecology, Faculty of Medicine, Kaduna State University, Kaduna, Nigeria \\ ${ }^{2}$ Department of Community Medicine, Faculty of Medicine, Kaduna State University, Kaduna, Nigeria \\ ${ }^{3}$ Department of Obstetrics and Gynaecology, Benue State University, Makurdi, Nigeria \\ ${ }^{4}$ Department of Obstetrics and Gynaecology, Ahmadu Bello University Teaching Hospital, Zaria, Nigeria \\ Email: *aminamhmd4@gmail.com
}

Received 4 December 2015; accepted 18 December 2015; published 23 December 2015

Copyright (C) 2015 by authors and OALib.

This work is licensed under the Creative Commons Attribution International License (CC BY).

http://creativecommons.org/licenses/by/4.0/

(c) (i) Open Access

\section{Abstract}

Background: Vaginal discharge is a common gynecological symptom seen among women provoking anxiety and fear of sexually transmitted infections (STIs). Methods: This was a hospital based retrospective study done from November 2008 to March 2013. Records of 969 patients presenting to the gynaecology clinic with symptoms of "vaginal discharge" were retrieved and relevant data on demographics, discharge characteristics and frequency, associated risk factors and symptoms, as well as investigations were retrieved. Data were analyzed using the statistical package for social sciences (SPSS) software, version 15. Relevant descriptive and bivariate analysis was done. Level of $p<0.05$ was considered statistically significant. Results: Majority of the patients (54.9\%) were aged between 21 and 30 years, and the mean age was $26.7 \pm 7.9$. More than half $(53.3 \%)$ were of the Hausa ethnic group, Muslims (82.6\%) and housewives (51.9\%). In terms of colour only $28.2 \%$ was characterized; more commonly as whitish $(16.9 \%)$ or milky (7.7\%). About 560 patients (57.8\%) had additional associated symptoms. The commonest organism cultured was Candida species in 252 patients (26\%), followed by Staphylococcus aureus (15.6\%) and Streptococcus species $(0.8 \%)$. When compared, those with additional symptoms were more likely to present with whitish vaginal discharge, candidiasis and recurrence of symptoms $(p<0.05)$, than those who had no additional symptoms. Conclusions: Vaginal discharge is a common symptom among women but may not always be pathological. Candidiasis was the commonest infectious cause in this population though the symptom needs to be properly characterized, and investigated when required.

\footnotetext{
*Corresponding author.
}

How to cite this paper: Amina, M.-D., Zainab, M.-I., Amina, A., Augustine, O. and Adebiyi, A. (2015) Pattern of Vaginal Discharge and Associated Demographic Characteristics among Female Patients Seen at a Gynaecology Clinic in Northern Nigeria. Open Access Library Journal, 2: e2231. http://dx.doi.org/10.4236/oalib.1102231 


\title{
Keywords
}

\section{Pattern, Vaginal Discharge, Northern Nigeria}

\author{
Subject Areas: Gynecology \& Obstetrics
}

\section{Introduction}

Vaginal discharge is a common gynecological condition among women of childbearing age that frequently requires care, and affects about one-third of all women and half of pregnant women [1]-[3]. In South Asia, about a quarter of all adult women report this complaint [4]. In Lagos [5], vaginal discharge was shown to be the commonest symptom of reproductive tract infections (STIs) (21.8\%) and that majority of women sought medical treatment for this symptom. Vaginal discharge provokes anxiety and fear that a woman may have STIs, and controlling the spread of STIs and HIV is a key public health priority worldwide [6].

Although vaginitis is not a serious condition in strict medical terms, it may have repercussions on a woman's quality of life [2], cause fear and anxiety that one may have a sexually transmitted disease, and is associated with substantial discomfort leading to frequent medical visits [7] which have economic implications [8].

The most common causes of altered vaginal discharge are physiological such as bacterial vaginosis (BV) and candidiasis. Other causes that must be considered include sexually transmitted infections (STIs), and less commonly, non-infective causes such as foreign bodies, cervical ectopy and genital tract malignancy [9].

What is regarded as physiological vaginal discharge is quite normal for healthy women of reproductive age. It is derived from the physiological secretions of the cervical and Bartholin's glands, as well as the desquamation of vaginal epithelial cells resulting from bacterial action in the vagina [1] [9]. The quantity and type of physiologic vaginal discharge may actually vary due to the hormonal fluctuations that occur during the menstrual cycle. About the time of ovulation, cervical mucus may appear to become clearer, more copious, have more stretch and be more slippery [9]. Stress increases the rate of vaginal desquamation and thus the amount of discharge [7]. Atrophic vaginitis must also be considered in the differential of vaginal discharge [7].

The rising estrogen levels seen at puberty can also lead to the colonization of the vagina with lactobacilli which metabolize glycogen and make the normal vaginal environment acidic, with a $\mathrm{pH}$ of $\leq 4.5$. Whenever this balance is disturbed, commensal organisms (such as Candida albicans, Staphylococcus aureus and Streptococcus agalactiae, Group B streptococcus) can cause a change in the character of vaginal discharge if they "overgrow" [9].

Vaginal discharge can also be pathological and all women with persistent vaginal discharge should be examined to exclude serious pathology [9]. Historically, vaginal discharge can be easily characterized by asking a woman questions related to: what has changed, onset, duration, odour, cyclical changes, colour, consistency, exacerbating or associated risk factors (e.g. after intercourse or menstruation, immunocompromised states, pregnancy, diabetes) and any other associated symptoms [9]. Abnormal vaginal discharge is usually more likely to be more abundant, have an associated unpleasant odor, and be accompanied by other symptoms such as vulvar or vaginal itching, dysuria, abdominal pain, and/or dyspareunia [1].

Vaginal discharge is not always investigated except when it is recurrent or history suggests a pathological cause. Various diagnostic methods are available to identify the etiology of an abnormal vaginal discharge ranging from simple tests like determining the $\mathrm{pH}$ and microscopic examination of fresh samples of the discharge ( $\mathrm{NaCl}$ and $\mathrm{KOH}$ wet mounts), Whiff test, to more complex microbiological culture and use of DNA probe and other rapid tests.

Women experiencing vaginal discharge who are at low risk of STI can be treated by syndromic or empirical management while those assessed as being at risk of STI, or who request testing should be offered appropriate tests for chlamydia, gonorrhoea, syphilis and HIV [9]. Ideally settings should have their own suitable local protocols for investigating and treating vaginal discharge.

Few studies have investigated vaginal discharge in this environment. Most studies done focus on either one etiologic causal agent or only the pregnant population. This study was done to determine the patterns of vaginal 
discharge seen among women in the study population, and to see how the symptom was characterized and investigated.

\section{Methodology}

This was a hospital based retrospective study. The study setting was the Kaduna polytechnic clinic and permission to use data was gotten from hospital authorities. The Kaduna polytechnic, a tertiary educational institution, is the largest polytechnic in Africa, South of the Sahara. The clinic caters for the primary and secondary healthcare needs of an estimated staff and student population of 50,000, as well as the general public. Most of the female students are of the reproductive age group. The study period was from November 2008 to March 2013. Records of 969 patients presenting to the gynaecology clinic with symptoms of "Vaginal discharge" was retrieved and relevant data on demographics, discharge characteristics and frequency, associated risk factors and symptoms, as well as investigations were retrieved. Information gotten was kept anonymous and no personal identifiers were disclosed to ensure patient confidentiality. Data was analyzed using the statistical package for social sciences (SPSS) software, version 15. Relevant descriptive and bivariate analysis was done. Levels of $\mathrm{p}<$ 0.05 was considered statistically significant.

\section{Results}

The gynaecology clinic records showed that a total of 969 female patients presented with a complaint of "vaginal discharge" during the study period. Majority of the patients (54.9\%) were aged between 21 and 30 years, the minimum age was 3 years, maximum age 54 years, and the mean age was $26.7 \pm 7.9$. More than half (53.3\%) were of the Hausa ethnic group, Muslims (82.6\%) and housewives (51.9\%). Demographic characteristics of patients are shown in Table 1.

Vaginal discharge was not always well characterized. In terms of colour only $28.2 \%$ was characterized as shown in Figure 1, and it was more commonly described as whitish (16.9\%) or milky (7.7\%). It was also described as yellowish (1.2\%), clear (0.8\%), brownish (1.3\%) bloody $(1.0 \%)$ and not characterized in $71.8 \%$ of cases. About 560 patients (57.8\%) had one or more additional associated symptoms; these included itching (35\%), abdominal pain (27.7\%), internal heat (0.7\%), vulva soreness (2.6\%), abnormal menstruation (5.9\%), rashes (4.5\%) and malodour (1.0\%).

About 126 (15.1\%) presented within a week of their last menstrual period, 34 (3.5\%) had recent antibiotic exposure, 19 (2\%) use antiseptic douches and 17 (1.8\%) were pregnant. Of the 253 single patients, only 49 reported about sexual activity and 44 were sexually active and 35 used condoms. Not all patients were investigated. Only 458 (47.3\%) patients had high vaginal swabs, and 511 (52.7\%) did not. The commonest organism cultured was Candida species in 252 patients (26\%), followed by Staphylococcus aureus (15.6\%) and Streptococcus species $(0.8 \%)$. Candida and Staphylococcus aureus occurred as a mixed infection in $6.7 \%$ of cases. In 112 patients (11.6\%) culture yielded no growth. About 144 patients had rapid HIV (human immunodeficiency virus) antibody testing and 127 (88.2\%) were non-reactive and 17 (11.8\%) were reactive). VDRL (venereal disease research laboratory test) for syphilis was done in 50 patients and were all non-reactive. Fasting blood sugar was done to screen for diabetes in 124 (12.8\%) patients and all had normal blood sugar levels except one.

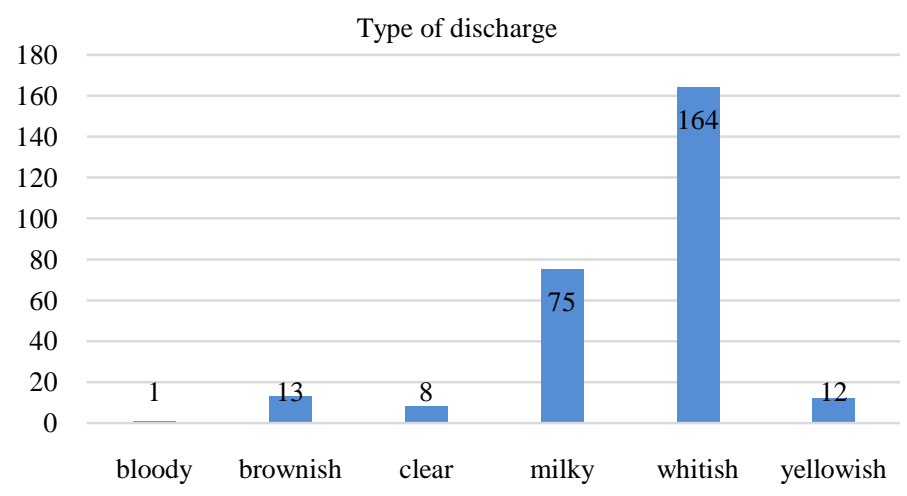

Figure 1. Type of vaginal discharge. 
Table 1. Demographic characteristics of patients.

\begin{tabular}{|c|c|c|}
\hline & Frequency & Percent \\
\hline \multicolumn{3}{|l|}{ Age (in years) } \\
\hline$<10$ & 14 & 1.4 \\
\hline $11-20$ & 177 & 18.3 \\
\hline $21-30$ & 532 & 54.9 \\
\hline $31-40$ & 167 & 17.2 \\
\hline $41-50$ & 49 & 5.1 \\
\hline$>50$ & 13 & 1.3 \\
\hline Missing & 17 & 1.8 \\
\hline \multicolumn{3}{|l|}{ Ethnic group } \\
\hline Hausa & 516 & 53.3 \\
\hline Igbo & 40 & 4.1 \\
\hline Yoruba & 130 & 13.4 \\
\hline Others & 254 & 26.2 \\
\hline Missing & 29 & 3.0 \\
\hline \multicolumn{3}{|l|}{ Religion } \\
\hline Islam & 800 & 82.6 \\
\hline Christianity & 167 & 17.2 \\
\hline Others & 0 & 0.0 \\
\hline Missing & 2 & 0.2 \\
\hline \multicolumn{3}{|l|}{ Marital status } \\
\hline Married & 712 & 73.5 \\
\hline Single & 253 & 26.1 \\
\hline Divorced/widowed & 3 & 0.3 \\
\hline Missing & 1 & 0.1 \\
\hline \multicolumn{3}{|l|}{ Occupation } \\
\hline Child & 14 & 1.4 \\
\hline Civil servant & 54 & 5.6 \\
\hline Youth corper & 2 & 0.2 \\
\hline Housewife & 503 & 51.9 \\
\hline Nurse & 1 & 0.1 \\
\hline Private business & 129 & 13.3 \\
\hline Student & 242 & 25.0 \\
\hline Tailor & 10 & 1.0 \\
\hline Teacher & 14 & 1.4 \\
\hline \multicolumn{3}{|l|}{ Parity } \\
\hline 0 & 45 & 4.6 \\
\hline $1-4$ & 138 & 14.2 \\
\hline$\geq 5$ & 107 & 11.0 \\
\hline Missing & 679 & 70.1 \\
\hline Total & 969 & 100 \\
\hline
\end{tabular}


There was no information recorded at all about a history of recurrence of "vaginal discharge" for 703 patients (72.5\%) while 57 (5.9\%) patients had never had the symptom in the past and 209 (21.6\%) had similar symptom in the past. Timeframe for recurrence of symptoms is shown in Table 2.

When compared, those with additional symptoms were more likely to present with whitish vaginal discharge, candidiasis and recurrence of symptoms $(\mathrm{p}<0.05)$ as shown in Table 3 than those who had no additional symptoms.

Table 2. Time frame for recurring symptom of "vaginal discharge".

\begin{tabular}{ccc}
\hline Average duration of recurrence & Frequency & Percent \\
\hline Within two weeks & 2 & 0.2 \\
One month & 6 & 0.6 \\
Two months & 80 & 8.3 \\
Three months & 26 & 2.7 \\
Six months & 6 & 0.6 \\
One year & 20 & 2.1 \\
Two years & 19 & 2.0 \\
Missing & 810 & 83.6 \\
Total & 969 & 100 \\
\hline
\end{tabular}

Table 3. Comparing symptoms to nature of vaginal discharge, HVS (high vaginal swab) results and history of recurrence.

\begin{tabular}{|c|c|c|}
\hline & $\begin{array}{l}\text { No additional } \\
\text { symptoms }\end{array}$ & $\begin{array}{l}\text { Had additional } \\
\text { symptoms }\end{array}$ \\
\hline \multicolumn{3}{|l|}{ Type of discharge } \\
\hline Not characterized & 261 & 435 \\
\hline Bloody & 0 & 1 \\
\hline Brownish & 0 & 13 \\
\hline Clear & 0 & 8 \\
\hline Milky & 59 & 16 \\
\hline Whitish & 87 & 77 \\
\hline Yellowish & 2 & 10 \\
\hline \multicolumn{3}{|l|}{$\chi^{2}=74.372, \mathbf{d f}=6, \mathbf{p}=0.000$} \\
\hline \multicolumn{3}{|l|}{ Result of HVS } \\
\hline Test not documented & 237 & 274 \\
\hline Candida only & 34 & 153 \\
\hline Candida and staphylococcus & 13 & 52 \\
\hline No growth & 73 & 39 \\
\hline Staphylococcus only & 44 & 42 \\
\hline Streptococcus only & 8 & 0 \\
\hline \multicolumn{3}{|l|}{$\chi^{2}=99.049, \mathbf{d f}=5, \mathbf{p}=0.000$} \\
\hline \multicolumn{3}{|l|}{ History of recurrence } \\
\hline Not stated & 291 & 412 \\
\hline No & 2 & 55 \\
\hline Yes & 116 & 93 \\
\hline$\chi^{2}=50.330, \mathbf{d f}=2, \mathbf{p}=0.000$ & & \\
\hline
\end{tabular}

Note: $\chi^{2}=$ chi Square, $\mathrm{df}=$ degree of freedom, $\mathrm{p}=\mathrm{p}$-value. 


\section{Discussion}

Vaginal discharge is a common symptom seen in clinics in Nigeria. Though vaginal discharge is one of the commonest symptoms of STIs [5], the association between it and the presence of RTIs may be weak [4].

In this study, vaginal discharge was commoner among those aged 21 to 30 years. This is similar to another study [8] that found a higher percentage of vaginal discharge in younger age and unmarried group. It is also consistent with findings from other studies [10] [11] and was attributed to higher incidence of sexual activity and contraceptive use among younger women. Sexual activity may have been under-reported in our study (44 out of 253 unmarried patients) as perceived promiscuity is stigmatized in our context. In contrast, studies elsewhere [12] found vaginal discharge to be more among females aged forty three and above (59.1\%).

Vaginal discharge was most commonly characterized as being white (16.9\%) which is similar to what was found in Saudi Arabia where white was the most common color of vaginal discharge, representing $50.8 \%$ of the complaints [2] and was not specific to a particular causative agent.

In our study, a high proportion (75.5\% or 346 out of 458 ) of patients were investigated by using high vaginal swabs resulted in an etiologic diagnosis. In India however, laboratory diagnosis was lower; 51.75\% [13], (2013) and 33.1\% [14]. High vaginal swabs (HVS) are often used to diagnose causes of vaginal discharge because they are more accessible to our labs, but they are actually of limited value [15] except in cases of inconclusive assessment, recurrent symptoms, treatment failure, or in pregnancy, postpartum, post-abortion or post-instrumentation [9].

Candidiasis was the commonest etiologic agent found in our study (26\%), followed by Staphylococcus (15.6\%). This is very similar to what was found in Kano, also in northern Nigeria [16], that among those with vaginal discharge of infective origin, Candida albicans was isolated in $94 \%$ of cases, while Staphylococcus aureus was isolated in $6 \%$. This is also similar to other studies were higher rates of candidiasis $(53.6 \%-75 \%)$ was found; [3] [10] [11] [17] [18].

The risk factors for candidiasis are well known and include douching, use of antibiotics, immunocompromised states and diabetes [9]. Few of the women studied had these risk factors. Though douching is a common cultural practice in this environment for personal hygiene, to prevent infections and as an aphrodisiac [19] [20]. The practice of douching is however discouraged [21]. Irrational use of antibiotics is also widespread [22]. Identification of species type would be useful especially in recurrent candida infection [9] but was not always done in this case. Roughly $80 \%$ of candidiasis are due to Candida albicans, while others are with other Candida species including Candida glabrata and Candida tropicalis. Some 15\% to 20\% of cases are however asymptomatic [7]. Recurring candidiasis without the common predisposing factors, may be an acquired candida-antigen specific cutaneous anergy in about $40 \%-70 \%$ of cases leading to a relapse rather than reinfection [7], especially when short treatment regimens are used. And in some cases, reinfection has been attributed to a persistent intestinal reservoir of candida [7].

One study [13], however found bacterial vaginosis to be commonest in 105 (26.25\%) women, and other infections were also common; candidiasis alone (61, 15.25\%), trichomoniasis alone (12, 3\%), mixed infections (22, $5.5 \%)$. Bacterial vaginosis was also commonest, $14.3 \%$ - 17.4\% according to some other [14] [23].

Apart from the type of tests available, results are also affected by the quality of the tests and lab procedures as well as experience of personnel. Facilities for some cultures, transport media and storage conditions are not always available or adequate in resources poor settings. Yet reporting of commensal bacteria can cause anxiety and lead to overtreatment while poor quality of tests may lead to under-diagnosis of other causative agents [9].

\section{Limitations of the Study}

Record keeping is generally poor in this part of the world. In this study uniform data of all women presenting to the clinic during the study period could not be reliable gotten to calculate actual prevalence. Characterization of vaginal discharge and educational level of patients was not well documented and missing data is a limitation of retrospective studies. The study is also facility based with a small sample size which may not necessarily reflect what obtains in the community. Lack of adequate laboratory resources limited investigation into causes of the symptom.

\section{Conclusion and Recommendation}

Vaginal discharge is a common symptom among women but it is significant to note that it may not always be 
pathological. Hence most women need to be educated and reassured to allay anxiety. Candidiasis was the commonest infectious cause in this population and was sometimes recurrent, so women should avoid its predisposing factors which are well known. More attention should be paid to proper record keeping, documentation of facts and improving laboratory services. More prospective and qualitative studies are needed to further study this symptom.

\section{References}

[1] da Fonseca, T.M.M.V., Cesar, J.A., Mendoza-Sassi, R.A. and Schmidt, E.B. (2013) Pathological Vaginal Discharge among Pregnant Women: Pattern of Occurrence and Association in a Population-Based Survey. Obstetrics and Gynecology International, 2013, Article ID: 590416. http://dx.doi.org/10.1155/2013/590416

[2] Al Quaiz, J.M. (2000) Patients with Vaginal Discharge: A Survey in a University Primary Care Clinic in Riyadh City. Annals of Saudi Medicine, 20, 302-306.

[3] Mitchell, H. (2004) Vaginal Discharge—Causes, Diagnosis, and Treatment. BMJ, 328, 1306. http://dx.doi.org/10.1136/bmj.328.7451.1306

[4] Patel, V., Pednekar, S., Weiss, H., Rodrigues, M., Barros, P., Nayak, B., et al. (2005) Why Do Women Complain of Vaginal Discharge? A Population Survey of Infectious and Pyschosocial Risk Factors in a South Asian Community. International Journal of Epidemiology, 34, 853-862. http://dx.doi.org/10.1093/ije/dyi072

[5] Rabiu, K.A., Adewunmi, A.A., Akinlusi, F.M. and Akinola, O.I. (2010) Female Reproductive Tract Infections: Understandings and Care Seeking Behaviour among Women of Reproductive Age in Lagos, Nigeria. BMC Women's Health, 10, 8. http://dx.doi.org/10.1186/1472-6874-10-8

[6] Glasier, A., Metin Gulmezoglu, A., Schmid, G.P., Garcia Moreno, C. and Van Look, P.F.A. (2006) Sexual and Reproductive Health: A Matter of Life and Death. Lancet, 368, 1595-1607. http://dx.doi.org/10.1016/S0140-6736(06)69478-6

[7] Carr, P.L., Felsenstein, D. and Friedman, R.H. (1998) Evaluation and Management of Vaginitis. Journal of General Internal Medicine, 13, 335-346. http://dx.doi.org/10.1046/j.1525-1497.1998.00101.x

[8] Patel, V., Weiss, H.A., Kirkwood, B.R., Pednekar, S., Nevrekar, P., Gupte, S., et al. (2006) Common Genital Complaints in Women: The Contribution of Psychosocial and Infectious Factors in a Population Based Cohort Study in Goa, India. International Journal of Epidemiology, 35, 1478-1485. http://dx.doi.org/10.1093/ije/dyl219

[9] Faculty of Sexual and Reproductive Healthcare (FSRH) (2012) Clinical Guidelines: Management of Vaginal Discharge in Non-Genitourinary Medicine Settings. Clinical Effectiveness Unit.

[10] Yusuf, A., Chowdhury, M., Islam, K.M.S., Eva, E.O., Sharif, A.R., Rahman, K., Talukder, A.R. and Begum, S.A. (2011) Common Microbial Etiology of Abnormal Vaginal Discharge among Sexually Active Women in Dhaka, Bangladesh. South East Asia Journal of Public Health, 1, 35-39.

[11] Nwodioha, S.I., Egah, D.Z., Alao, O.O. and Ihenacho, E. (2010) Risk Factors for Vaginal Candidiasis among Women Attending Primary Healthcare Centers of Hos, Nigeria. Journal of Clinical Medicine Research, 2, 110-113.

[12] Chaudhary, V., Kumar, R., Agrawal, V.K., Singh, A., Narula, R. and Sharma, M. (2012) Prevalence and Determinants of Vaginal Discharge among Women of Reproductive Age Group in Tertiary Care Hospital of Northern India. National Journal of Community Medicine, 3, 661-665.

[13] Sivaranjini, R., Jaisankar, T.J., Thappa, D.M., Kumari, R., Chandrasekhar, L., Malathi, M., Parija, S.C. and Habeebullah, S. (2013) Spectrum of Vaginal Discharge in a Tertiary Care Setting. Tropical Parasitology, 3, 135-139. http://dx.doi.org/10.4103/2229-5070.122140

[14] Prabha, M.L.S., Sasikala, G. and Bala, S. (2012) Comparison of Syndromic Diagnosis of Reproductive Tract Infections with Laboratory Diagnosis among Rural Married Women in Medak District, Andhra Pradesh. Indian Journal of Sexually Transmitted Diseases, 33, 112-115.

[15] Jungmann, E., Johnson, A.M., Ridgway, G., Durrant, K. and Robinson, A.J. (2004) How Useful Are High Vaginal Swabs in General Practice? Results of a Multicentre Study. International Journal of STD \& AIDS, 15, 238-239. http://dx.doi.org/10.1258/095646204773557758

[16] Omole-Ohonsi, A. and Nwokedi, E.E. (2004) Sociodemographic Characteristics and Aetiological Factors of Vaginal Discharge in Pregnancy. Jos Journal of Medicine, 5, 27-30.

[17] Nessa, K., Warris, S.A., Alam, A., Hug, M., Nahar, S., Chawdhury, F.A.H., et al. (2005) Sexually Transmitted Infections among Brothel-Based Sex Workers in Bangladesh: High Prevalence of Asymptomatic Infection. Sexually Transmitted Diseases, 32, 13-19. http://dx.doi.org/10.1097/01.olq.0000148298.26228.74

[18] Sobel, J.D., Faro, S., Force, R.W., Foxman, B., Ledger, W.J., Nyirjesy, P.R., et al. (1998) Vulvovaginal Candidiasis: Epidemiologic, Diagnostic and Theraputic Considerations. American Journal of Obstetrics \& Gynecology, 178, 203- 
211. http://dx.doi.org/10.1016/S0002-9378(98)80001-X

[19] Mohammed-Durosinlorun, A. (2008) Kayan Mata: The Secret World of Aphrodisiacs in Northern Nigeria. Project Submitted to the ARSRC. Sexuality in Africa Magazine and Monographs, 5, 12-13.

[20] Mairiga, A.G., Kullima, A.A. and Kawuwa, M.B. (2010) Social and Health Reasons for Lime Juice Vaginal Douching among Female Sex Workers in Borno State, Nigeria. African Journal of Primary Health Care \& Family Medicine, 2, $1-4$.

[21] Cottrell, B.H. (2010) An Updated Review of Evidence to Discourage Douching. MCN: The American Journal of Maternal/Child Nursing, 35, 103-110. http://dx.doi.org/10.1097/NMC.0b013e3181cae9da

[22] Israel, E.U., Sylvester, E.G. and Akwaowoh, A.E. (2015) The Use of Antibiotics in a Nigerian Tertiary Health Care Facility. American Journal of Biomedical Science and Engineering, 1, 25-31.

[23] Patnaik, L., Sahu, T. and Sahani, N.C. (2008) Syndromic Diagnosis of RTI/STI among Women of Reproductive Age Group. Indian Journal of Community Medicine, $4,1$. 